\title{
Analisis Kesan Frekuensi dan Sudut Dongakan terhadap Pelemahan Hujan di Malaysia
}

(Frequency Effects and the Elevation Angle Analysis of the Rain Attenuation in Malaysia)

Teh Sieh Ting, Ooi Wei Chun \& J. S. Mandeep*

ABSTRAK

Kesesakan spektrum jalur frekuensi yang telah ditetapkan sejak sekian lama telah mendorong kepada penggunaan frekuensi yang lebih tinggi iaitu melebihi $10 \mathrm{GHz}$ bagi memenuhi kehendak dan keperluan para pengguna. Namun demikian, operasi di jalur frekuensi ini akan menyebabkan sistem lebih mudah terdedah kepada kehilangan isyarat akibat dari fenomena alam semulajadi seperti hujan lebat. Disebabkan oleh kesan pudaran hujan, ramalan pelemah hujan menggunakan taburan kadar hujan 1-minit menjadi semakin penting. Ramai penyelidik telah mencadangkan pelbagai jenis model ramalan untuk menganggar pelemahan hujan di seluruh dunia. Namun demikian, tidak ada model yang sesuai yang boleh meramalkan pelemah hujan dengan tepat. Di Universiti Sains Malaysia (USM), model International Telecommunication Union-Region (ITU-R) telah menunjukkan ramalan yang terbaik berbanding model-model yang lain. Model ITU-R digunakan untuk menganalisis kesan-kesan pelemahan hujan pada frekuensi dan sudut dongakan yang berbeza. Daripada analisis yang telah dilakukan, didapati bahawa peningkatan frekuensi operasi dan penurunan dalam sudut dongakan akan mengakibatkan peningkatan dalam pelemahan hujan. Namun demikian penjelasan seperti di atas boleh dilihat bagi sudut dongakan melebihi ketinggian $50^{\circ}$.

Kata kunci: Taburan hujan; kadar hujan; satelit; jalur $K_{u}$

ABSTRACT

Congestion on frequency spectrum that was predetermined long time ago has stimulated the use of frequency above than $10 \mathrm{GHz}$ in order to fulfil the needs and requirements of the customers. However, operating at this frequency band will cause the system to be more easily susceptible to signal loss due to natural phenomena such as heavy rain. Because of the fading effects, accurate prediction of rain induced attenuation by using 1-min rainfall rate becomes important. Many researchers have proposed various types of predictive models to estimate the rain attenuation over the world. However, there is no appropriate model that can predict the rain attenuation accurately. At Universiti Sains Malaysia (USM), the International Telecommunication Union model-Region (ITU-R) has shown the best prediction compared to other models. ITU-R model is used to analyze the effects of rain attenuation at different frequency and elevation angles. From the analysis, it was found that as the frequency of operation increases and the angle of elevation reduces, this would result in an increase in rain attenuation. However, the above clarification may be seen for elevation angles above $50^{\circ}$ elevation.

Keywords: Rainfall distribution; rainfall; satellite; $K_{u}$ band

\section{PENGENALAN}

Penggunaan teknologi perkhidmatan jalur lebar iaitu internet berkelajuan tinggi, video digital, audio penyiaran, persidangan video dan lain-lain menyebabkan perkembangan pesat dalam bidang radio komunikasi. Dengan permintaan yang semakin meningkat, penggunaan jalur lebar yang lebih besar dan rangkaian data yang pantas melebihi $10 \mathrm{GHz}$ amatlah diperlukan dalam sistem komunikasi satelit. Beberapa jalur frekuensi seperti Jalur$\mathrm{Ku}(12-18 \mathrm{GHz})$ dan Jalur-Ka (27-40GHz) digunakan untuk penghantaran satelit supaya para pelanggan dapat menikmati perkhidmatan rangkaian data yang pantas dan berkapasiti tinggi (Thompson et al 2011). Namun demikian, pada jalur frekuensi yang lebih tinggi, hujan merupakan punca pelemahan yang serius dalam perambatan gelombang radio (Chebil \& Rahman 1999). Ini adalah kerana dengan meningkatnya frekuensi, panjang gelombangmenghampiri saiz titisan hujan, di mana titisan hujan bertindak sebagai skrin pantulan untuk gelombang tersebut. Hujan lebatboleh menjejaskan kualiti penghantaran dan menghadkan prestasi sesuatu rangkaian satelit pada frekuensi $10 \mathrm{GHz}$ dan keatas. Fenomena ini menjadi semakin kritikal di kawasan di mana kadar hujan adalah tinggi, iaitu kawasan tropika, khususnya di kawasan khatulistiwa. Keadaan ini akan menyebabkan perkhidmatan satelit gagal berfungsi untuk jangka masa tertentu. Oleh yang demikian, hujan 
merupakan satu faktor yang signifikan untuk pereka sistem gelombang mikro dalam membuat peramalan yang tepat tentang pelemahan hujan.

Hujan akan menjejaskan penghantaran isyarat elektromagnet dalam tiga bentuk iaitu melemahkan isyarat elektromagnet, meningkatkan sistem hingar dan menukarkan pengutuban isyarat (Robert 2000). Ketigatiga faktor ini akan menyebabkan kemerosotan dalam kualiti isyarat yang diterima jika isyarat tersebut dihantar dalam bentuk analog atau meningkatkan kadar ralat bit jika penghantaran dalam bentuk digit (Oh et al 2002). Faktorfaktor ini memainkan peranan yang semakin penting apabila frekuensi pembawa semakin meningkat. Pada Jalur-C, kesan pelemahan hujan adalah kecil dan pada Jalur-Ku, kesan pelemahan hujan menjadi semakin ketara dan tidak boleh diabaikan. Namun pada frekuensi yang lebih tinggi seperti Jalur-Ka atau Jalur-V, kemerosotan menjadi semakin signifikan dan tidak boleh diselesaikan mengikut kaedah yang biasanya digunakan untuk frekuensi yang lebih rendah (Robert 2000). Pengetahuan tentang kadar hujan 1-minit diperlukan kerana kadar hujan 1-minit akan digunakan dalam model pelemahan hujan. Menurut cadangan Telekomunikasi Antarabangsa Union (ITU), taburan kumulatif kadar hujan dengan masa integrasi 1-minit diperlukan sebagai input utama kepada model pelemahan hujan (Zhou et al. 2009). Disebabkan oleh sifat hujan yang pantas berubah pada kawasan tertentu, taburan kumulatif kadar hujan yang diperhatikan akan bergantung kepada masa pensampelan yang berkesan untuk tolok hujan.

Oleh itu, bagi mengekalkan prestasi pengoperasian sistem satelit, para jurutera sistem komunikasi perlu mereka bentuk antena berdasarkan Analisis Pautan Bajet (Link Budget Analysis, LBA). LBA mengambil kira semua gandaan dan kehilangan yang akan menyebabkan perubahan terhadap isyarat yang merambat dari satelit ke stesen bumi. Kehilangan terbesar yang terlibat dalam bajet ini adalah kehilangan laluan (path loss), dimana kehilangan laluan adalah jumlah pelemahan isyarat yang berlaku semasa penghantaran dari satelit ke stesen bumi.

Namun demikian, kekurangan kefahaman terhadap proses hujan dan kekurangan data hujan daripada tapak pengukuran menyusahkan para jurutera rekabentuk membuat ramalan yang tepat terhadap pelemahan hujan. Manuskrip ini mengkaji perubahan sudut dongakan dan frekuensi di tempat pengukuran di Universiti Sains Malaysia (USM) bagi tahun 2009 bagi melihat perubahan pelemahan hujan apabila sudut dongakan dan frekuensi berubah. Perbandingan model-model hujan di kawasan pengukuran telah pun dibuat oleh Mandeep \& Hassan (2008a), Mandeep \& Hassan (2008b) dan Mandeep (2009) dan didapati bahawa model ITU-R dibuktikan sebagai model yang paling berkesan berbanding model-model lain seperti dalam rujukan (Mandeep \& Hassan, 2008a; Mandeep \& Hassan, 2008b; Mandeep, 2009). Model tersebut diaplikasikan dengan pelbagai frekuensi dan sudut dongakan bagi melihat trend perubahan pelemahan hujan.

\section{KAEDAH KAJIAN}

Sebelum memulakan pengukuran, terdapat beberapa parameter yang perlu ditentukan. Stesen utama yang digunakan untuk mengukur data hujan bagi eksperimen ini terletak di Universiti Sains Malaysia (USM), Nibong Tebal, Pulau Pinang dengan Lat. $5.17^{0} \mathrm{~N}$ dan Long. $100.4^{0} \mathrm{E}$. USM terletak kira-kira $7 \mathrm{~km}$ dari laut dan kira-kira $57 \mathrm{~m}$ di atas paras laut purata. Di stesen utama dengan melihat ke arah satelit SUPERBIRD-C di $144^{\circ} \mathrm{E}$, sudut dongak antena penerima adalah $40^{\circ}$ manakala sudut azimut antena penerima adalah $95^{\circ}$. Frekuensi pautan turun sistem tersebut adalah 12.255 $\mathrm{GHz}$. Antena penerima yang digunakan berbentuk piring parabola dengan garis pusatnya $2.4 \mathrm{~m}$ dengan sudut ofset $72.5^{\circ}$. Isyarat dari satelit SUPERBIRD-C diterima oleh piring antena yang disambung ke penukar blok hingar rendah (low noise block converter, LNBC). Isyarat satelit yang berada pada jalur- $\mathrm{K}_{\mathrm{u}}$ ditukar ke frekuensi perantaraan iaitu jalur-L menggunakan LNBC. Keluaran daripada LNBC kemudian disambung ke penganalisis spektrum untuk memantau isyarat pembawa dan mengasingkan isyarat hingar. Isyarat keluaran daripada penganalisis spektrum disambung ke pencatat data yang disambung dengan komputer menggunakan perisian LabVIEW. Perisian ini telah diprogramkan untuk merekod puncak 60 sampel berturut-turut dengan tempoh persampelan 1 saat. Perisian ini mengira nilai purata untuk nilai-nilai puncak 60 sampel dan memberi nilai puncak purata dalam 1-minit.

Untuk mengukur kadar hujan di kawasan daratan, tolok hujan baldi tip digunakan untuk mengukur hujan yang diterima dan disambung ke komputer menggunakan sistem KisyoDisp.Untuk menjalankan analisis terhadap kadar hujan, data kadar hujan hendaklah diwakili dalam bentuk peratusan masa. Data peratusan masa untuk jumlah tempoh ujian boleh diperolehi berdasarkan formula berikut (Moupfouma 1987):

$$
\begin{aligned}
& t=\sum_{i=1}^{N} \delta_{i} \\
& P(\%)=\frac{t}{T} \times 100 \%
\end{aligned}
$$

di mana

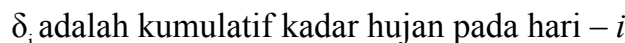
$t$ adalah jumlah masa eksperimen bagi kadar hujan berlebihan

$T$ adalah jumlah tempoh eksperimen

$P$ adalah peratusan masa untuk jumlah tempoh ujian

\section{KEPUTUSAN DAN PERBINCANGAN}

Kawasan tropika seperti negara Malaysia biasanya mengalami hujan lebat sepanjang tahun dan taburan hujan bagi negara ini dicorakkan berdasarkan aktiviti monsun. Merujuk kepada Jabatan Meterologi Malaysia, cuaca di Malaysia boleh dikategorikan kepada tiga jenis, iaitu Monsun Barat Daya (southwest monsoon), Monsun 
Timur Laut (northeast monsoon) dan jangka pendek monsun perantaraan (intermonsoon period). Monsun Barat Daya berlaku dari akhir bulan Mei hingga September dan Monsun Timur Laut dari November hingga Mac. Manakala monsun perantaraan ialah tempoh peralihan antara dua monsun ini iaitu berlaku pada bulan April dan Oktober. Antara monsun-monsun ini, Monsun Timur Laut merupakan musim hujan utama bagi negara Malaysia. Monsun Timur Laut yang berlaku dari bulan November hingga Mac ini, akan bertiup dari Laut China Selatan dan membawa hujan yang lebat kepada negeri-negeri yang terletak di Pantai Timur Semenanjung Malaysia dan Barat Sarawak. Jabatan Meteorologi Malaysia juga mencatatkan bahawa Monsun Timur Laut memberikan kadar hujan yang paling tinggi di negara Malaysia kerana angin yang ditiup dari Laut China Selatan tidak dihalang oleh sebarang rintangan seperti pulau, semenanjung atau gunung. Sistem cuaca monsun yang terbentuk bersama dengan luruan udara sejuk dari Siberia akan menghasilkan hujan yang lebat, di mana seringkali mengakibatkan berlakunya banjir besar sepanjang pantai timur Malaysia (Suhaila dan Jemain, 2007; Tangang, 2001; Suhaila dan Jemain, 2009).

Pelemahan hujan amat bergantung kepada jalur frekuensi yang digunakan. Sebagai contohnya, pada $4 \mathrm{GHz}$ iaitu frekuensi bagi pautan turun Jalur-C, pelemahan semasa hari cerah adalah lebih kurang $0.4 \mathrm{~dB}$ dan apabila hujan turun iaitu lebih kurang $10 \mathrm{~mm} / \mathrm{h}$, pelemahan akibat daripada hujan akan meningkat sedikit kepada $0.5 \mathrm{~dB}$. Bagi frekuensi di bawah Jalur-C, biasanya nilai pelemahan boleh diabaikan. Ini merupakan salah satu sebab frekuensi Jalur-S, Jalur-L dan VHF digunakan bagi pautan sistem mudah alih (mobile links) dan TT\&C (Telemetry, Tracking \& Command). Walaubagaimanapun, masalah akan timbul bagi frekuensi operasi yang melebihi $10 \mathrm{GHz}$. Bagi Jalur$\mathrm{K}_{\mathrm{u}}(10 \mathrm{GHz}-18 \mathrm{GHz})$, pelemahan semasa hari cerah adalah kurang dari $1 \mathrm{~dB}$, tetapi apabila hujan turun, pelemahan boleh meningkat setinggi $10 \mathrm{~dB}$. Kesan pelemahanakan menjadi semakin teruk sekiranya kadar hujan semakin tinggi. Oleh itu, operasi yang menggunakan Jalur-Ku adalah lebih mudah terdedah kepada kesan pelemahan berbanding Jalur-C. Situasi akan menjadi semakin teruk apabila operasi menggunakan Jalur-Ka (20-30GHz). Pelemahan semasa hari cerah tidak begitu signifikan, tetapi apabila hujan, pelemahan boleh meningkat dengan mendadak sehingga mencapai 30-50dB.Justeru, frekuensi juga dikenalpasti sebagai salah satu punca yang signifikan dalam penentuan pelemahan hujan.

Oleh itu, kajian telah dibuat terhadap pelbagai frekuensi seperti $11 \mathrm{GHz}$ (Jalur-X), 18GHz (Jalur-Ku), 24GHz (Jalur-K), 30GHz (Jalur-Ka), 40GHz (Jalur-Q), $60 \mathrm{GHz}$ (Jalur-U), 80GHz (Jalur-E) dan 100GHz (Jalur-W) bagi mengkaji trend pelemahan hujan. Model hujan digunakan untuk menganggarkan jumlah degradasi (atau pudar) isyarat apabila melalui titisan hujan. Kemerosotan ini adalah disebabkan oleh penyerapan oleh molekul air dan pergantungan kepada fungsi frekuensi dan sudut dongakan. Secara umumnya, kehilangan hujan akan meningkat dengan peningkatan frekuensi manakala pelemahan hujan bagi laluan condong di kawasan beriklim sederhana akan meningkat dengan pengurangan dalam ketinggian sudut dongakan. Perubahan laluan pelemahan dengan sudut dongakan di antara $10^{\circ}$ dan $50^{\circ}$ secara amnya dianggap menghampiri hukum kosekans (Bowthorpe et al. 1990; Arnold et al. 1981). Rajah 1 menunjukkan spesifik pelemahan berlawan dengan kadar hujan bagi pelbagai frekuensi. Manakala Rajah 2 menunjukkan spesifik pelemahan hujan berlawan dengan frekuensi bagi pelbagai kadar hujan. Kedua-dua rajah ini diplot berdasarkan model ITU-R.

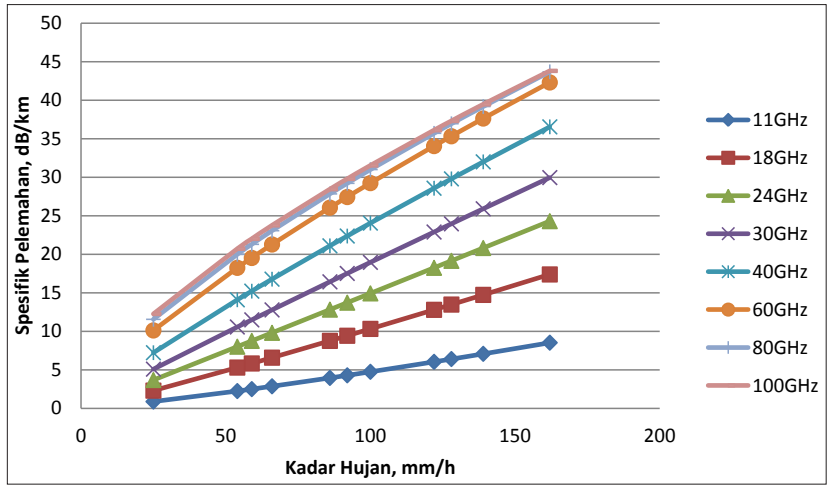

RAJAH 1. Spesifik Pelemahan berlawan dengan Kadar Hujan bagi pelbagai frekuensi

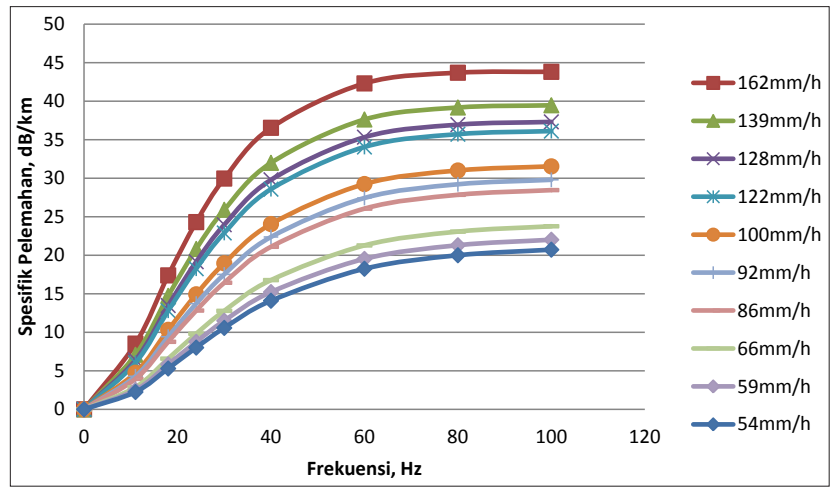

RAJAH 2. Spesifik pelemahan berlawan dengan frekuensi bagi pelbagai kadar hujan

Daripada Rajah 1, boleh dilihat bahawa semua graf menunjukkan peningkatan secara linear tanpa bergantung kepada nilai frekuensi yang digunakan. Sebagai contohnya, pada operasi frekuensi $18 \mathrm{GHz}$, apabila kadar hujan ialah $25 \mathrm{~mm} / \mathrm{h}$, spesifik pelemahan yang dihasilkan ialah $0.882 \mathrm{~dB} / \mathrm{km}$ tetapi sekiranya kadar hujan ditingkatkan bersamaan dengan $162 \mathrm{~mm} / \mathrm{h}$, spesifik pelemahan setinggi $17.385 \mathrm{~dB} / \mathrm{km}$ akan terhasil. Oleh itu, boleh dirumuskan bahawa peningkatan terhadap pelemahan hujan bergantung tinggi terhadap nilai kadar hujan yang berlaku. Manakala, Rajah 2 menunjukkan bahawa apabila nilai kadar hujan dimalarkan, spesifik pelemahan akan dipengaruhi oleh peningkatan frekuensi. Peningkatan operasi frekuensi ini akan mengakibatkan isyarat elektromagnet mudah diserap dan bertaburan ketika melalui titisan hujan dan 
menyebabkan peningkatan bagi nilai spesifik pelemahan. Hal ini berlaku kerana jumlah nilai relatif bagi spesifik pelemahan adalah bergantung kepada nisbah jejari titisan hujan ke panjang gelombang. Dengan kata lain, semakin tinggi frekuensi operasi, semakin kecil panjang gelombang dan ini menyebabkan spesifik pelemahan meningkat.

Seperti yang dinyatakan sebelum ini, model ramalan juga bergantung tinggi terhadap sudut dongakan antena yang digunakan. Justeru itu, dalam sub-bahagian ini, pengaplikasian terhadap pelbagai sudut dongakan dari $10^{\circ} \mathrm{ke} 90^{\circ}$ telah dibuat untuk melihat perubahan trend pelemahan hujan. Rajah 3 menunjukkan rumusan kesan pelbagai sudut dongakan terhadap pelemahan hujan. Rajah ini juga diplot berdasarkan model ITU-R.

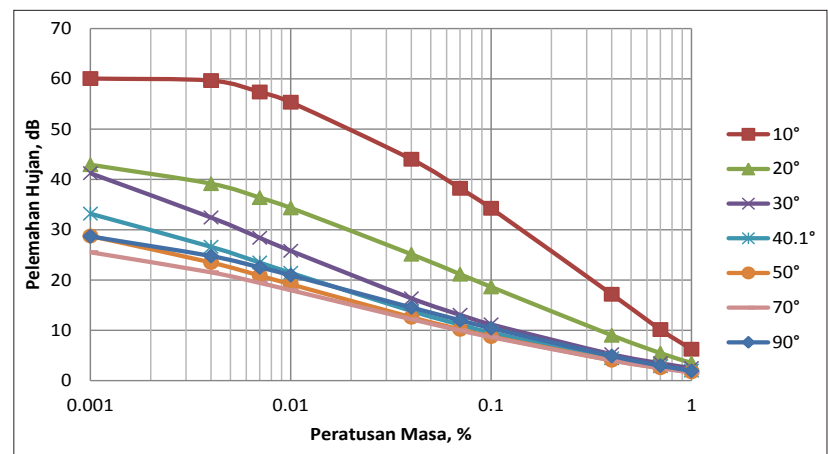

RAJAH 3. Pelemahan hujan berlawan dengan peratusan masa bagi pelbagai sudut dongakan

Rajah 3 menunjukkan bahawa pelemahan hujan yang terhasil adalah berubah secara songsang dengan sudut dongakan yang digunakan. Perubahan pelemahan hujan ini dianggap menghampiri hukum kosekans di mana teori hukum kosekans ini bergantung pada andaian bahawa lapisan pelemahan terdiri dari struktur stratiform. Sebagai contohnya, daripada Rajah 3, pada sudut dongakan $10^{\circ}$ dengan peratusan masa $0.01 \%$, pelemahan hujan yang terhasil adalah sebanyak $55.35 \mathrm{~dB}$, tetapi apabila sudut dongakan ditingkat kepada $30^{\circ}$ dengan peratusan masa yang sama, pelemahan hujan yang terhasil hanyalah $25.80 \mathrm{~dB}$. Dengan kata lain, semakin rendah sudut dongakan, semakin tinggi pelemahan hujan yang dihasilkan. Perkara ini berlaku adalah kerana penurunan dalam sudut dongakan akan meningkatkan jarak laluan condong melalui hujan serta menyebabkan peningkatan pelemahan hujan yang terhasil. Pernyataan ini lebih mudah difahami melalui ilustrasi yang ditunjukkan di dalam Rajah 4.

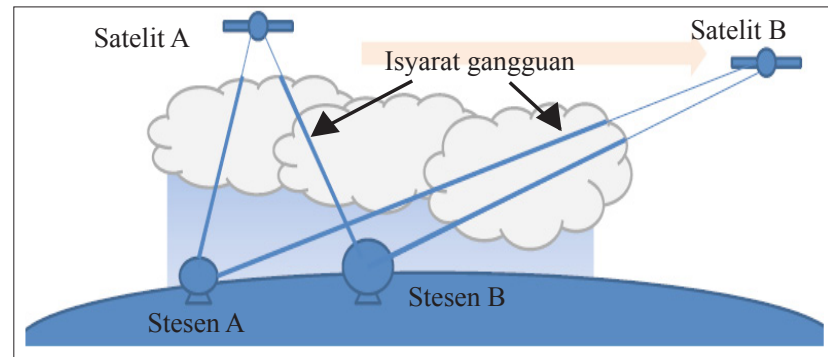

RAJAH 4. Sudut dongakan dan jarak laluan condong bagi sistem satelit
Namun demikian, hukum kosekans ini hanyalah diikuti dari sudut dongakan $10^{\circ}$ hingga $50^{\circ}$. Teori hukum kosekans ini menjadi kurang tepat apabila diaplikasikan terhadap sudut dongakan yang lebih tinggi (Arnold et al. 1981). Sebagai contoh, daripada Rajah 3 pada sudut dongakan $50^{\circ}$ dengan peratusan masa $0.04 \%$, pelemahan hujan yang terhasil adalah $12.6 \mathrm{~dB}$, tetapi apabila sudut dongakan ditingkatkan kepada $90^{\circ}$ dengan peratusan masa yang sama, pelemahan hujan yang terhasil adalah sebanyak $14.54 \mathrm{~dB}$. Sudut dongakan yang tinggi mempunyai pelemahan yang lebih besar kerana kebarangkalian kejadian hujan perolakan di kawasan tropika adalah lebih tinggi jika dibandingkan dengan kawasan-kawasan beriklim sederhana. Oleh itu, Malaysia sebagai salah satu negara berkawasan tropika juga akan mengalami masalah yang sama. Justeru itu, sudut dongakan yang sesuai perlu dipilih dengan teliti sebelum pemasangan antena.

\section{KESIMPULAN}

Pelbagai frekuensi dan sudut dongakan yang digunakan turut diaplikasikan bagi menganalisis kesan-kesan yang terlibat dengan mengkaji trend pelemahan hujan. Secara umumnya, daripada analisis yang telah dilakukan, didapati bahawa peningkatan frekuensi operasi dan penurunan dalam sudut dongakan akan mengakibatkan peningkatan dalam pelemahan hujan. Namun demikian, bagi sudut dongakan melebihi ketinggian $50^{\circ}$, pelemahan hujan yang terhasil akan semakin meningkat.

PENGHARGAAN

Penulis ingin mengucapkan terima kasih kepada Universiti Kebangsaan Malaysia, Universiti Sains Malaysia, dan Persatuan Industri Perniagaan Radio (ARIB) daripada Jepun dengan menyediakan peralatan pengukuran bagi mengumpul data-data hujan.

RUJUKAN

Arnold, H. W., Cox, D. C. \& Rustako, A. J. 1981. Rain attenuation at $10-30 \mathrm{GHz}$ along earth-space paths: elevation angle, frequency, seasonal, and diurnal Effects. IEEE Transactions on Communications 29(25): 716-721.

Bowthorpe, B. J., Andrews, F. B., Kikkert, C. J. \& Arlett, P. L. 1990.Elevation angle dependence in tropical region. International Journal of Satellite Communication 8: 211-221.

Chebil, J. \& Rahman, T. A. 1999.Rain rate statistical conversion for the prediction of rain attenuation in Malaysia. Electronics Letters Online 35: 1019 - 1021.

Mandeep, J. S. \& Hassan, S. I. S. 2008a. Rainfall effects on $\mathrm{Ku}$-band satellite link design in rainy tropical climate. Journal of Geophysical Research 113: D05107. 
Mandeep, J. S. \& Hassan, S. I. S. 2008b. Rainfall measurements at $\mathrm{Ku}$-Band Satellite Link in Penang. IET Microwave, Antenna and Propagation 2 (2):147151.

Mandeep, J. S. 2009. Comparison of rainfall models with $\mathrm{K}_{\mathrm{u}}$ band beacon measurement. Acta Astronautica 64 (2-3): 264-271.

Moupfouma, F. 1987. Rain induced attenuation prediction model for terrestrial and satellite-Earth microwave links. Annales des Télécommunications 42(9-10): 539550.

Oh, H. J., Sohn, B. J., Smith, E. A., Turk, F. J., Ae-suk, S. \& Chung, H. S. 2002. Validating infrared-based rainfall retrieval algorithms with 1-minute spatially dense raingauge measurements over Korean peninsula. Meteorlogy Atmospheric Physics 81: 271 - 287.

Robert, A. N. 2000. Rain - How it affects the communications link. Via Satellite.

Suhaila, J. \& Jemain, A. A. 2007.Fitting daily rainfall amount in Malaysia using the normal transform distribution. Journal Applied Science 7: 1880-1886.

Suhaila, J. and Jemain, A. A. 2009. Investigating the impacts of adjoining wet days on the distribution of daily rainfall amounts in Peninsular Malaysia. Journal Hydrology 368:17-25.

Tangang, F. T. 2001. Low frequency and quasi-biennial oscillations in the Malaysian precipitation anomaly. International Journal Climatology 21: 1199-1210.
Thompson, P., Evans, B., Castanet, L., Bousquet, M., \& Mathiopoulos, T. 2011.Concepts and Technologies for a Terabit/s Satellite. SPACOMM: The Third International Conference on Advances in Satellite and Space Communications, 12-19. Budapest, Hungary.

Zhou, X. X., Lee, Y. H. \& Ong, J. T. 2009.Conversion model of one-minute rainfall rate distribution in Singapore. Antennas and Propagation Society International Symposium, 4. 1-5 June 2009.

Teh Sieh Ting, Ooi Wei Chun \& J. S. Mandeep

Jabatan Kejuruteraan Elektrik, Elektronik dan Sistem Fakulti Kejuruteraan dan Alam Bina

Universiti Kebangsaan Malaysia

43600 UKM Bangi

Selangor, Malaysia

Penulis koresponden: emel: mandeep@eng.ukm.my

Serahan: 4 Julai 2013

Diterima: 4 Disember 2013 
